\title{
2021 Zuckerkandl Prize
}

\author{
David A. Liberles ${ }^{1} \cdot$ Michelle M. Meyer $^{2} \cdot$ Joshua S. Rest $^{3} \cdot$ Ashley I. Teufel $^{4}$
}

(c) Springer Science+Business Media, LLC, part of Springer Nature 2021

This year, 2021 marks the third year in a row that the reinstated Zuckerkandl Prize has been awarded. This is an award for the top paper published in Journal of Molecular Evolution to appear in a print issue during the calendar year, as judged by a committee, in honor of Founding Editor Emile Zuckerkandl. The award committee consisting of Michelle Meyer, Joshua Rest, and Ashley Teufel was assembled and the entire editorial board was polled for nominations to the committee.

Among the papers that were nominated, three received particularly serious discussion from the committee. The runner-up papers are listed below and reflect important advance in molecular evolution. Brintnell et al. (2021) presented a timely evolutionary study indicating that SARS-CoV2 was preadapted to infect humans. Moyer et al. (2021) presented a new tool for studying the evolution of metabolic networks with promising utility towards a greater understanding of the general rules of the nature of metabolic capabilities and structures in different organisms.

I am pleased to announce that "Pheromone gene diversification and the evolution of courtship glands in plethodontid salamanders" by Herrboldt, Steffen, McGouran, and Bonett (Herrboldt et al. 2021) is the Zuckerkandl Prize Award winner for 2021. This study integrates our understanding of duplicate gene fates with comparative salamander biology in showing how subfunctionalization contributed to differences in courtship glands in different species, with implications for the genotype-phenotype map of courtship differences between species. This integrative study brings together analysis from the molecular and more organismal levels with transcriptomic data to better understand lineage-specific biology. Journal of Molecular Evolution is proud to congratulate the authors on this work and the award.

\section{References}

Brintnell E, Gupta M, Anderson DW (2021) Phylogenetic and ancestral sequence reconstruction of SARS-CoV-2 reveals latent capacity to bind human ACE2 receptor. J Mol Evol 89:656-664. https:// doi.org/10.1007/s00239-021-10034-0

Herrboldt MA, Steffen MA, McGouran CN, Bonett RM (2021) Pheromone gene diversification and the evolution of courtship glands in plethodontid salamanders. J Mol Evol 89:576-587. https://doi. org/10.1007/s00239-021-10026-0

Moyer D, Pacheco AR, Bernstein DB, Segrè D (2021) Stoichiometric modeling of artificial string chemistries reveals constraints on metabolic network structure. J Mol Evol 89:472-483. https://doi. org/10.1007/s00239-021-10018-0

David A. Liberles

daliberles@temple.edu

1 Department of Biology and Center for Computational Genetics and Genomics, Temple University, Philadelphia, PA 19122, USA

2 Department of Biology, Boston College, Chestnut Hill, MA 02467, USA

3 Department of Ecology and Evolution, Stony Brook University, Stony Brook, NY 11794, USA

4 Department of Life Sciences, Texas A\&M University- San Antonio, San Antonio, TX 78224, USA 